\title{
Case Study: Topography Integrated Urban Center Concept Project on Coastal Line of Kartal/istanbul
}

\author{
Bahadır Mert ÇINAR \\ Architect / İstanbul, Turkey \\ ORCID: 0000-0003-1221-2759
}

\begin{abstract}
The concept of creating a Topography integrated urban center is to create an urban center that integrated with the city. The first step of the Concept is to settle by using the natural elevation in the land and to create volumes compatible with land by raising together with the elevation. While the passenger circulation at starting elevation is moved into a project with the cavestyle volume settled in land elevation. The new area of the square to be defined in the center of the building is intended to form an area combining the neighboring squares Kartal Square and Freedom Square, as well as contributing to the silhouette of Kartal from the sea with the location of the square and building. The project is a central complex design that deals with various urban problems thanks to professionals, local people of Kartal, and clubs which established with the municipality in a comprehensive way to search for solutions to be organized urban workshops and conferences.

Key words: Urban Center; Topography integrated; Sustainable Building; Blending with Topography; Walkable Green Roofs; Serving to People; 7/24 Living Place
\end{abstract}

Publication date: September, 2020

Publication online: 30 September, 2020

*Corresponding author: Bahadir Mert ÇINAR, bahadir.mert.cinar@gmail.com

\section{Introduction}

As hard as it is to describe to laypeople, what architects do, it may be even harder to define the idea of urban design and describe what urban designers do. Many of the residents of cities used to a system where the city "just happens" and where what happens to the city is the result of politics and who has the power and not the result of masterplans or designs or big ideas. Too discredited are the modernists' models of garden cities and new towns that well-intended as they were proved to be sterile and even anti-urban. Currently, many settlements with "Tactical Urbanism" are revealed as a way of using quick and bottom-up responses to shape cities rather than big ideas from the top.

Christopher Alexander, Introduction of "A New Theory of Urban Design"

"When we look at the most beautiful towns and cities of the past, we are always impressed by a feeling that they are somehow organic.' (http://archplanbaltimore. blogspot.com/2014/11/what-is-urban-design.html)

\subsection{Reporting Land and Non-Reporting Land}

- The land, for which the data on classification of landuse is available, is regarded as reporting land (White et al. 2016).

\subsection{Cultivable Land and Uncultivable Land}

- According to the available land-use statistics, there has been a slight increase in the net sown area. Almost 28 million hectares have been added over the passing few decades. Nearly 5 percent of the land falls in the category of uncultivated land (White et al. 2016).

\subsection{Urban design creates green, sustainable places.}

Compact, walkable places are the most sustainable form of living. The combination of human scale urbanism, with a mix of uses and services, a range of housing options, extensive train systems, and the ability to walk and bicycle as part of daily life all make for sustainable, green living (White et al. 2016). 


\section{Urban Sustainability}

There are a few places that worse for the environment than a city. Huge numbers of people coming and going, driving cars, and shopping for products, while factories pump all kinds of pollution into the atmosphere. Sustainability is the ability of our planet and our resources to endure forever, or a way of living without actively using our resources. Urban sustainability refers to building cities that can continue without running out of resources.

The urban environment has unique challenges when it comes to sustainability. Growing cities require more land and buildings. Outer-city areas can build up just as quickly as inner-city areas, while suburban boundaries can expand. This rapid development makes sustainable growth more difficult.

Urban sustainability is the idea that a city can be organized without excessive reliance on the surrounding countryside and be able to power itself with renewable sources of energy. The aim of this is to create the smallest possible ecological footprint and to produce the lowest quantity of pollution possible, to efficiently use the land, compost used materials, recycle it or convert waste-to-energy, and to make the city's overall contribution to climate change minimal.

It is estimated that over $50 \%$ of the world's population now lives in urban areas and that this will rise to $70 \%$ by 2050 . This is a tremendous change that will have an impact both on the millions of people that move and on the cities that they move into. Such a change provides planners and developers with a challenge. However, cities also offer opportunities; humans are social creatures. We thrive in urban spaces that encourage social connections.

Some experts think that cities will be the growth drivers of the future, stimulating both supply and demand in the economy. Cities need many things but they can provide many things as well. This provides opportunities for employment and economic success.

However, things can go wrong in cities. If their systems are not well organized or maintained they can have a large negative impact on the environment; they may use large amounts of energy that have been generated in unsustainable ways, they may scar and poison the land and pollute the atmosphere.

Technology has a large part to play in enabling positive outcomes for cities. The solutions are being developed today will be critical in ensuring that the cities of tomorrow represent a

What does it mean to be a sustainable city? A sustainable city or eco-city (also "ecocity") is a city designed with consideration of environmental impact, inhabited by people dedicated to minimization of required inputs of energy, water and food, and waste output of heat, air pollution - $\mathrm{CO} 2$, methane, and water pollution (Große et al. 2016).

\section{TOPOGRAPHY INTEGRATED URBAN CENTER CONCEPT}

\subsection{Location (Shores of Istanbul / Turkey)}

The idea of the sustainable Urban Centers in coastal lines of Istanbul is decided its first project to locate on Kartal / Istanbul on an area of 24,500 m2 adjacent to Kartal Square and Freedom Square, west of the old town hall, behind the former suburban line, in a passage located between the coastline and the city(Figure 1).
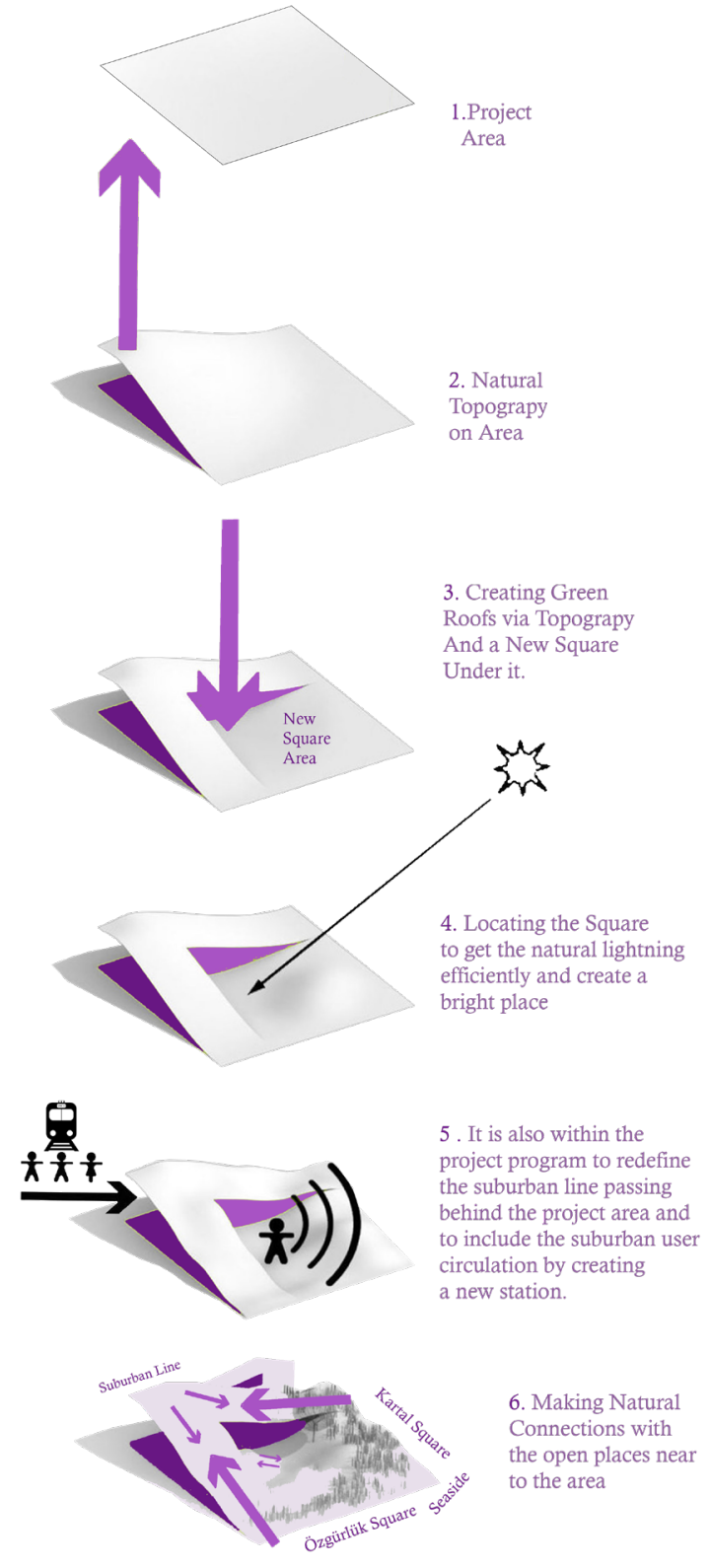

Figure 1 


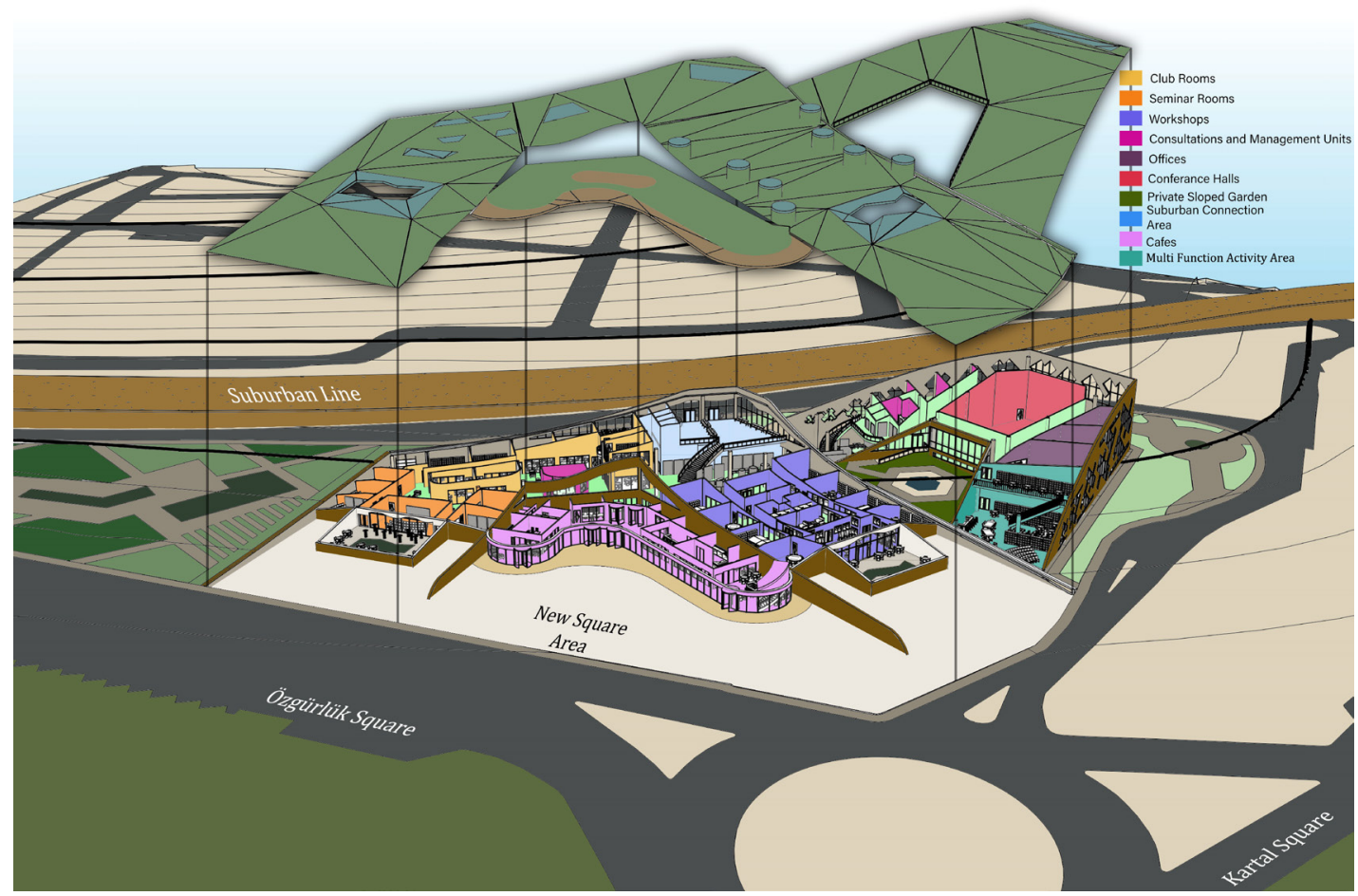

Figure 2

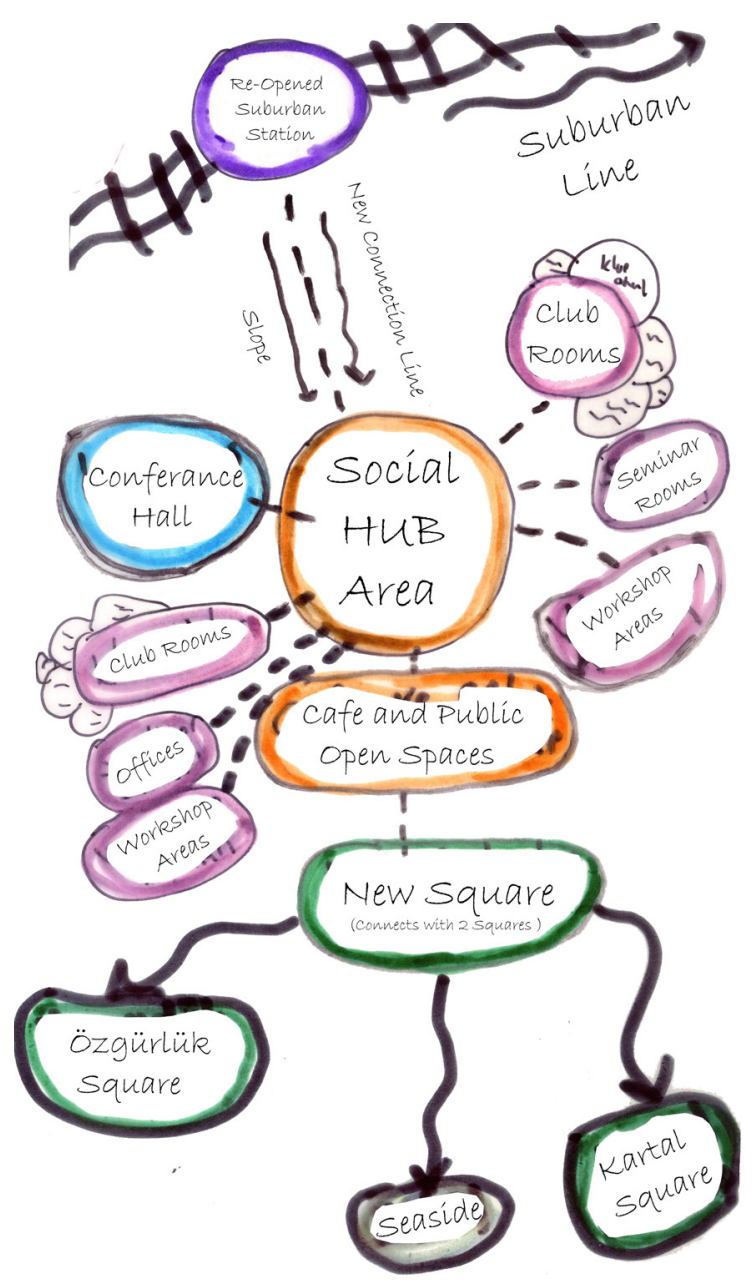

Figure 3

\subsubsection{What 'Miesto' Means in Center Miesto Kartal?}

The word Miesto means Urban in Lithuanian Language. It also means Living with the city.

\subsubsection{Urban Concept on the Project in Kartal}

The concept of topography integrated urban center design is to create an urban center that is integrated with the city. The first step of the project is to settle by using the natural elevation in the land and to create volumes compatible with land by raising together with the elevation. While the passenger circulation at starting elevation is moved into a project with the cave-style volume settled in land elevation, the former suburban line behind the project area is also restored and it is aimed at providing to the building the task of welcoming Kartal. The new area of the square to be defined in the center of the building is intended to form an area combining the neighboring squares Kartal Square and Freedom Square, as well as contributing to the silhouette of Kartal from the sea with the location of the square and building. (Figure2,3)

\subsection{Urban Design}

The aims of the Topography integrated urban design; to create an urban club center that uses land level efficiently, where green architecture will come to the fore and urban problems will be handled together with local people, professionals and social clubs (water 


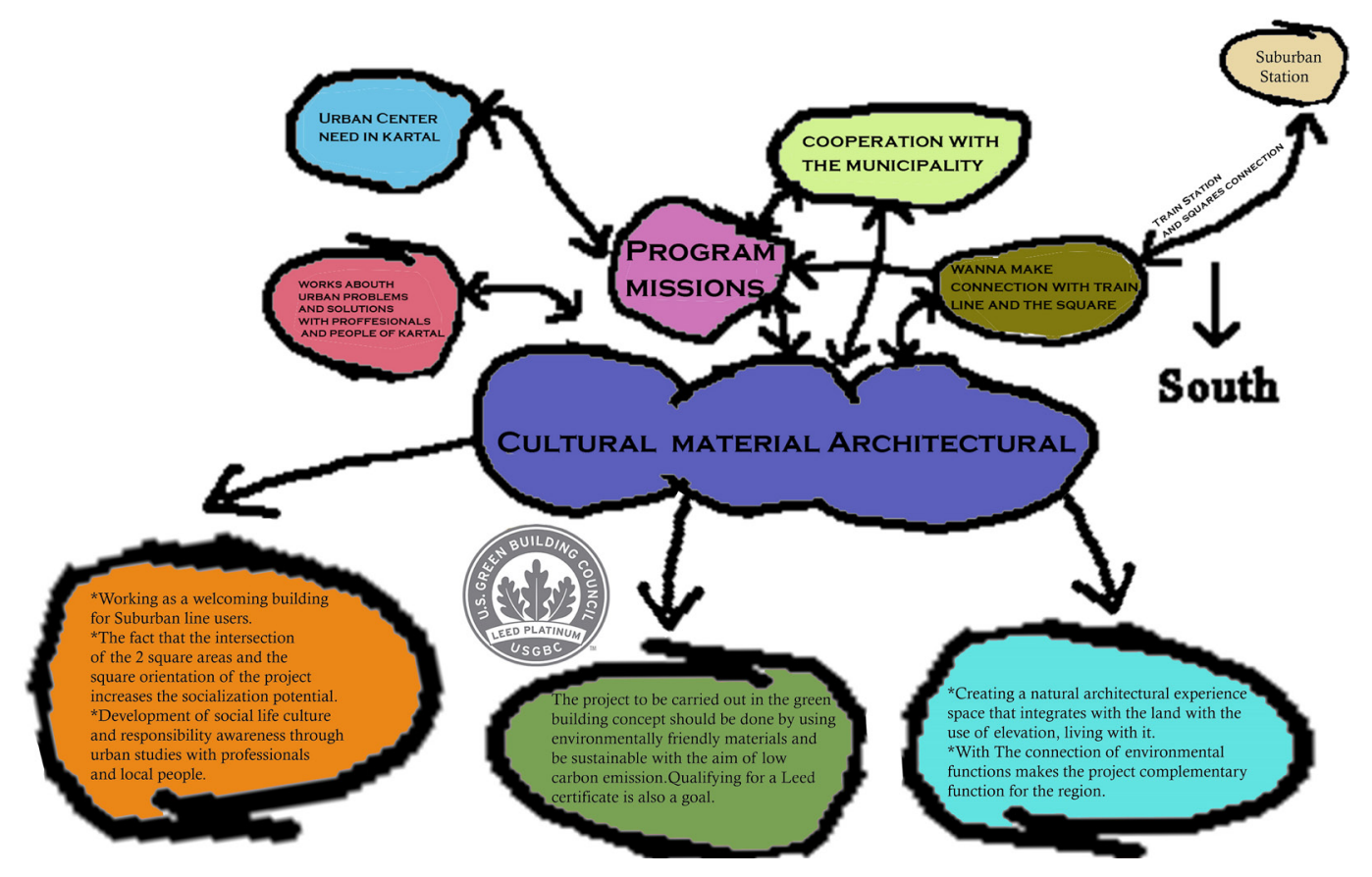

Figure 4

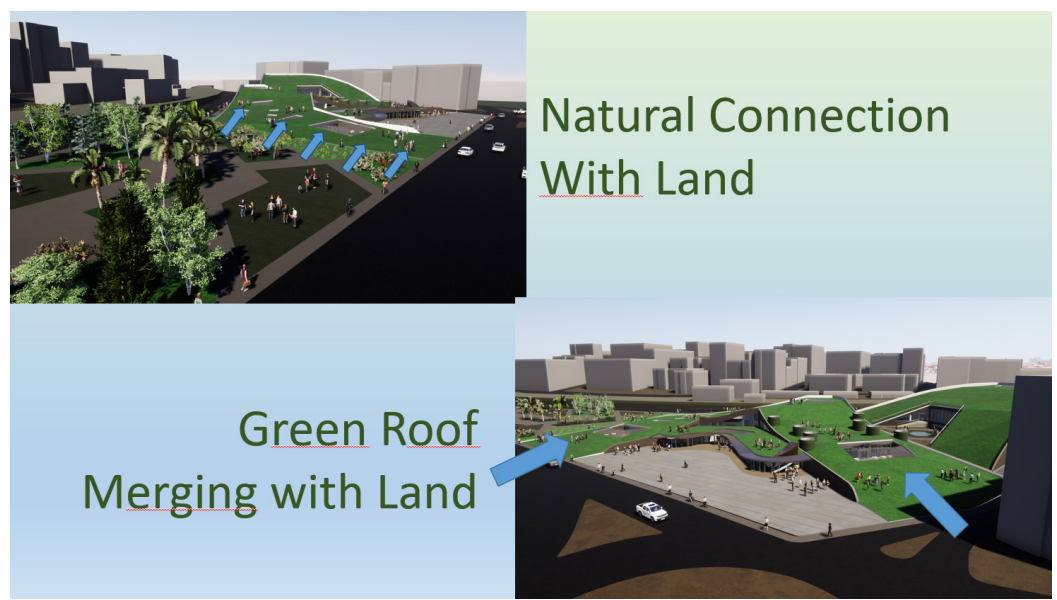

Figure 5

pollution, urban landscape, and design problems, excessive concrete, etc.). Conventions, seminars, and urban topics organized in this center will be carried out jointly with the municipality. It is also within the project program to redefine the suburban line passing behind the project area and to include the suburban user circulation by creating a new station. (Figure4,5)

\subsection{Aims of the Urban Complex}

Kartal Topography integrated Urban Center is a central complex that deals with various urban problems thanks to professionals, local people of Kartal, and clubs which established with the municipality in a comprehensive way to search for solutions to be organized urban workshops and conferences. (Figure 3)

\subsection{Program Elements of the Urban Center}

The program elements of the project include clubs, seminar rooms, workshops, conference areas, offices, connecting areas with suburban passenger circulation of Kartal, common and private social areas, special education garden, square and parking areas, cafe, and socializing areas. (Figure 2)

\subsection{Concept's Contributions to its Area and Urban Environment}

Important Road Connections to Kartal Urban Center Project.

New Defined Connection Point.

Regaining its Function back to old Suburban Station.

Giving Suburban User Circulation inside of the Urban Center.

Connecting New Defined Square with the other two 
squares.

Contributing to the city's silhouette due to its location.

Becoming and Welcoming Place for Suburban and Kadıköy Coastal Line Users.

\subsection{Urban Goals}

Among the cultural goals of the project; Examples of such activities include increasing the socialization potential of the new square by joining other nearby squares, increasing the awareness of users on urban responsibility for collective and voluntary activities, determining urban changes with the active participation of local people as well as professionals and providing a more comprehensive understanding of the city.

\subsection{Sustainability Goals}

With the green building concept, to make the project by using environmentally friendly materials and to be a sustainable structure by targeting low carbon emission and in accordance with these criteria, the building to be entitled to receive the LEED certification from the international environmental building scaling system has been aimed.

\section{Seasons Sustainable and Living Place - A Urban Center for People and City. (Figure $6,7,8)$}

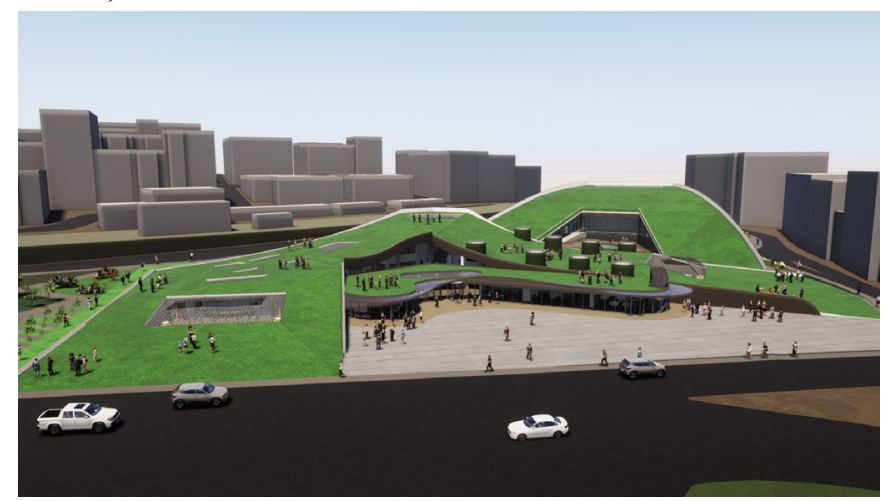

Figure 6

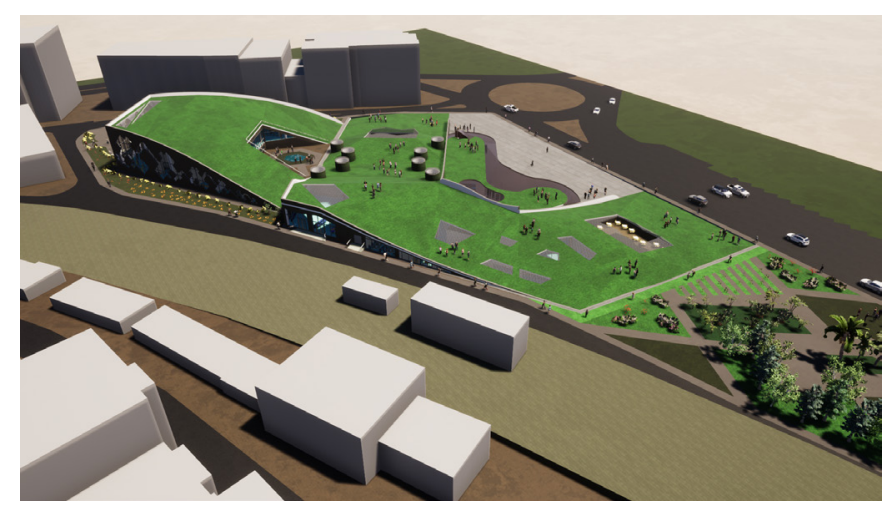

Figure 7

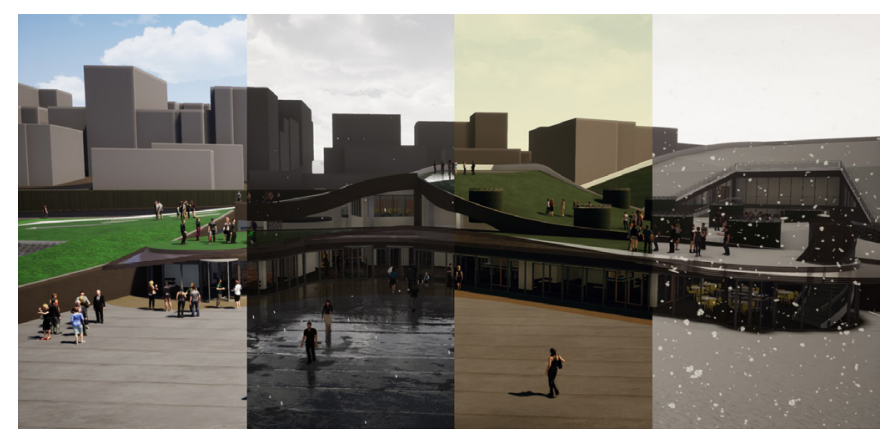

Figure 8

\section{Conclusion}

Current Studies Shows that there is an important need for Kartal in terms of completing the region by establishing a functional relationship that integrates with the area where the project location. To meet most city's needs for the Urban Center and to be a sustainable structure is aimed at sheds light on the future of the city and strengthening the awareness of urban responsibility of people.

\section{References}

[1] http://www.urbandesign.org/sustainable.html. The center for desing excellence.

[2] Marcus White \& Youpei Hu \& Nano Langenheim \& Wowo Ding \& Mark Burry, (2016). "Cool City Design: Integrating Real-Time Urban Canyon Assessment into the Design Process for Chinese and Australian Cities," Urban Planning, Cogitatio Press, vol. 1(3), pages 25-37. DOI: http://dx.doi.org/10.17645/ up.v1i3.646

[3] http://www.urbandesign.org/sustainable.html. The center for desing excellence.

[4] Große, J., Fertner, C.,\& Groth, N.B.(2016). Urban Structure, Energy and Planning: Findings from Three Cities in Sweden, Finland and Estonia. Urban Planning,1(1),24-40. DOI: http:// dx.doi.org/10.17645/up.v1i1.506 